\title{
Lung deposition of aerosol-a comparison of different spacers
}

\author{
H J Zar, E G Weinberg, H J Binns, F Gallie, M D Mann
}

\begin{abstract}
Aims-To investigate (1) aerosol lung deposition obtained from two small volume conventional spacers (Babyhaler and Aerochamber) and a home made spacer (modified $500 \mathrm{ml}$ plastic cold drink bottle); (2) the effect of using a face mask or mouthpiece; and (3) the relation between age and pulmonary deposition.

Methods-Lung deposition of aerosolised technetium-99m DTPA inhaled via spacer was measured in 40 children aged 3-7 years with stable asthma. Each patient performed sequential randomly assigned inhalations using two spacers. Three studies were performed: Babyhaler compared to Aerochamber (with facemasks); Babyhaler with facemask compared to Babyhaler with mouthpiece; and Babyhaler with mouthpiece compared to a $500 \mathrm{ml}$ bottle.

Results-Median lung aerosol deposition from a Babyhaler and Aerochamber with masks were similar $(25 \%$ v $21 \%, p=0.9)$. Aerosol lung deposition from a Babyhaler with mask compared to a Babyhaler with mouthpiece was equivalent $(26 \% v 26 \%$, $\mathbf{p}=0.5)$. Lung deposition was higher from a $500 \mathrm{ml}$ bottle compared to a Babyhaler in both young $(25 \% v 12.5 \%, \mathrm{p}=0.005)$ and older children $(42 \%$ v $22.5 \%$, $\mathbf{p}=0.003)$. A notable reduction in pulmonary deposition occurred at 50 months of age.
\end{abstract}

Conclusion-A Babyhaler or Aerochamber produce equivalent lung deposition of aerosol. There is no difference in lung deposition when a mask or mouthpiece is used. A modified $500 \mathrm{ml}$ plastic bottle produces greater pulmonary aerosol deposition than a conventional small volume spacer.

Department of

Paediatrics and Child

Health, Red Cross War

Memorial Children's

Hospital, University of

Cape Town, Cape

Town, South Africa

$\mathrm{H} \mathrm{J}$ Zar

E G Weinberg

H J Binns

F Gallie

M D Mann

Correspondence to:

Dr H Zar, Child Health

Unit, 46 Sawkins Road,

Rondebosch, 7700, South

Africa

email: heather@

rmh.uct.ac.za

Accepted 4 February 2000 maintenance therapy for childhood asthma. A provides the optimal system for delivery of spacer, used in conjunction with an MDI improves drug delivery to the lungs and significantly reduces local and systemic side effects from drugs, especially inhaled corticosteroids. ${ }^{12}$ Recent studies suggest that an MDI with spacer is also the preferred delivery system for children with acute asthma. ${ }^{3}$ Equivalent or better bronchodilatation is obtained when $\beta_{2}$ agonists are delivered via MDI with spacer compared to nebulisation in children with acute asthma, even when the degree of airways obstruction is severe. ${ }^{4}$

Young children with asthma are unable to use an MDI effectively without the addition of a spacer. Small volume spacers such as the Babyhaler (GlaxoWellcome) and Aerochamber (Trudell Medical, Canada) have been developed for this purpose. These spacers consist of a facemask connected to a cylindrical extension device via a one way valve. The facemask can be replaced by a mouthpiece. Home made spacers, principally a $500 \mathrm{ml}$ plastic cold drink bottle have been adapted for use in developing countries. ${ }^{5}$ Although these spacers are widely used there is little data on their comparative efficacy or on the effect of a mouthpiece compared to a facemask for delivery of aerosolised medication.

We have previously developed a system to measure aerosol lung deposition from different spacers in older children. ${ }^{5}$ This technology was adapted $^{6}$ in order to: (1) compare lung deposition of aerosol from the Babyhaler and Aerochamber; (2) investigate the effect of a facemask or mouthpiece on lung deposition of aerosol; (3) compare pulmonary aerosol deposition obtained from the Babyhaler and modified $500 \mathrm{ml}$ plastic bottle; and (4) examine the relation between age and pulmonary deposition.

\section{Methods}

PATIENTS

Forty patients with moderate asthma who regularly attend the asthma clinic at Red Cross Children's Hospital, participated in the study. Inclusion criteria were a requirement for regular inhalation therapy for control of asthma, absence of an acute asthma exacerbation within the preceding six weeks, and age 3-5 years (studies 1-3) or 5-7 years (study 3 only). Patients were excluded if they had clinical signs or symptoms of airways obstruction on the day of the test. In addition, children older than 5 years had a peak expiratory flow rate of greater than $85 \%$ of the predicted normal value on the day of the study. Informed consent was obtained from a parent or legal guardian. The study was approved by the Ethics Review Committee, UCT Medical School.
DELIVERY AND MEASUREMENT OF AEROSOL

Technetium-99m DTPA (code N108, Amersham International plc, Amersham, UK) aerosol was used to measure deposition in the lungs. The delivery system consisted of a 2 litre anaesthetic rebreathing bag, which could be sealed. A two way tap (isolation valve) of the type used in medical gas lines was attached to 
the proximal end of the bag and a gas flow controller from a Baumanometer to the distal end. The bag was filled with aerosol by connecting it to a micro Cirrus nebuliser (Amersham Health Care code N 1430, Amersham International plc, Amersham, UK) with a $1 \mathrm{~m}$ length of corrugated respirator tubing and passing oxygen vertically up through the nebuliser, corrugated tubing, and bag at a flow rate of $6 \mathrm{l} / \mathrm{min}$ for a minimum of 10 minutes. A plastic tube on the flow valve on the distal end of the bag carried all aerosol passing through the bag to a trapping system. The bag was sealed by closing the Baumanometer flow valve and then the two way tap before being removed from the circuit and attached by this tap to the particular spacer device being tested.

The activity available for inhalation was calculated from static one minute images of the bag recorded before and after the patient breathed from the delivery system and spacer combination. Deposition of aerosol in the lungs was calculated from a dynamic series of posterior images recorded at one second per frame for two minutes while the patient breathed deeply from the spacer and attached bag. In all children activity in the lungs had reached plateau within 40 seconds and total counts in the lung in the second minute of the study were taken as total pulmonary activity.

Each patient performed two separate inhalations in order to compare the efficacy of different spacers. The spacers were tested in two sequential inhalations. Immediately before beginning the second inhalation, the residual activity in the patient's lungs was measured and later subtracted from the total pulmonary activity measured in the second study. Subtraction of residual activity was necessary to obtain an accurate measurement for aerosol lung deposition from the second spacer.

\section{SPACERS}

Two conventional spacers (Babyhaler, Glaxo Wellcome; and Aerochamber, Trudell Medical) and a home made spacer (500 $\mathrm{ml}$ plastic cold drink bottle) were tested. The Babyhaler is a $350 \mathrm{ml}$ polycarbonate spacer with low resistance inspiratory and expiratory valves, a removable facemask, and $40 \mathrm{ml}$ of dead space between the inlet and outlet valve. The Aerochamber is a $145 \mathrm{ml}$ plastic spacer with an attached facemask and no dead space between the valves. An MDI container was placed in the open ends of each conventional spacer. The

Table 1 A comparison of aerosol deposition from different spacers in children

\begin{tabular}{llll}
\hline Spacer & Median & $95 \%$ CI & p value \\
\hline Study 1 & 25 & $15.2-28.6$ & 0.9 \\
Babyhaler with mask & 21 & $18.1-27.3$ & \\
Aerochamber with mask & 26 & $21.4-36.6$ & 0.5 \\
Study 2 & $22.0-31.4$ & \\
Babyhaler with mask & & \\
Babyhaler with mouthpiece & 26 & $6.5-19.5$ & 0.005 \\
Study 3 & & $19.7-31.5$ & \\
Age 3-5 years & 12.5 & $15.9-27.7$ & 0.003 \\
$\quad$ Babyhaler with mouthpiece & 25 & $36.0-44.0$ & \\
$\quad$ Ag0 mil bottle & & \\
$\quad$ Babyhaler with mouthpiece & 22.5 & 42 & \\
$\quad$ 500 ml bottle &
\end{tabular}

Values expressed as percentage aerosol deposition.
MDI-canister was replaced by a tightly fitting rubber stopper into which the connector from the anaesthetic bag was inserted via a small opening.

A $500 \mathrm{ml}$ plastic cold drink bottle was modified as has been described previously. ${ }^{57} \mathrm{~A}$ hole was melted in the base of the bottle to tightly fit the connector from the anaesthetic bag. The bottle-connector perimeter was sealed with glue. Newly constructed bottle spacers were washed with soap and water and air dried in order to reduce electrostatic charge on the side walls. The neck of the bottle was held in the child's mouth, simulating a mouthpiece.

STUDIES

Three studies were performed in order to minimise the potential for unecessary exposure to radiation. In the first study, the Babyhaler with facemask was compared to the Aerochamber with facemask in children aged 3-5 years. In the second, the Babyhaler with facemask was compared to the Babyhaler with a mouthpiece in children aged 3-5 years. The mouthpiece was created by removing the mask and using the connector from the body of this spacer as a mouthpiece. In the third study the Babyhaler with mouthpiece was compared to a $500 \mathrm{ml}$ bottle in two groups of children aged 3-5 years and 5-7 years, respectively. In each study and in each patient the order of spacers was randomly assigned.

STATISTICAL ANALYSIS

Statistical analysis was performed using the Statistical Package for the Social Sciences (SPSS). Differences in drug delivery from the spacers in a single study were planned comparisons and assessed for significance using the Wilcoxon matched pairs test.

\section{Results}

The median (95\% confidence intervals) ages of children in the first, second, and third studies were 52 (47-56), 51 (44-54), and 61 (54-72) months respectively. In the third study, children in the younger (3-5 year) group were 46 (42-51) months while those in the older group were 79 (75-85) months.

Table 1 summarises the results of lung deposition of aerosol. The median (95\% confidence intervals) aerosol deposition in the lungs from the Babyhaler and Aerochamber with facemasks was 25\% (15.2-28.6) and 21\% (18.127.3) respectively, which were not significantly different. Median aerosol deposition from the Babyhaler with mask compared to the Babyhaler with mouthpiece was the same $(26 \%$ in both). However, aerosol lung deposition was significantly higher from a $500 \mathrm{ml}$ bottle compared to the Babyhaler with mouthpiece for both young (25\% (19.7-31.5) compared to $12.5 \%(6.5-19.5), \mathrm{p}=0.005)$ and older children $(42 \%(36.0-44.0)$ compared to $22.5 \%$ (15.9-27.7), $\mathrm{p}=0.003)$.

The age of the child affected the amount of aerosol deposited in the lungs, with decreased deposition occurring in younger children. At approximately 50 months of age, there was a notable reduction in the amount of pulmonary 


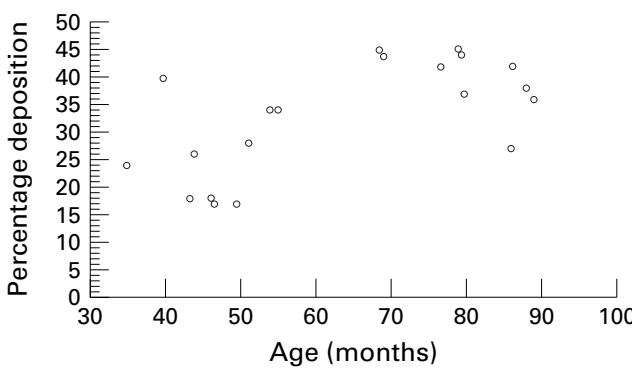

Figure 1 Pulmonary aerosol deposition from a bottle used as a spacer by age.

deposition obtained when the bottle was used as a spacer (fig 1). Of the children younger than 50 months of age, one had pulmonary deposition of more than $30 \%$, while only a single child older than 50 months had deposition less than $30 \%$. This pattern of deposition was similar for the Babyhaler but at a lower level. For the Babyhaler, only one child younger than 55 months had deposition of more than 19\%, while seven of 10 children older than 55 months had deposition of more than $19 \%$. Children in the 3-5 year age group of the third study were younger than those in the second study; this probably accounts for the lower aerosol deposition obtained from a Babyhaler in the former study.

\section{Discussion}

This study showed that a modified $500 \mathrm{ml}$ plastic bottle produced greater pulmonary aerosol lung deposition than a small volume conventional spacer, the Babyhaler. This effect was seen in children of various ages. Two widely available small volume spacers, the Babyhaler and Aerochamber produced equivalent aerosol lung deposition in young children. Furthermore, aerosol deposition did not differ whether a mask or mouthpiece was used.

Many properties of a spacer may affect pulmonary deposition of aerosol, including the volume and shape of the device, the electrostatic charge of the side walls, volume of dead space, and presence or type of valves. ${ }^{8-10}$ The efficiency of a $500 \mathrm{ml}$ bottle may be partly a result of its physical characteristics. A $500 \mathrm{ml}$ bottle was selected in preference to a larger volume bottle as it more closely approximates the optimum chamber dimensions for a spacer for children (experimentally found to be a cylinder approximately $11 \mathrm{~cm}$ in length by $3.5 \mathrm{~cm}$ in diameter). ${ }^{8}$ Furthermore, a $500 \mathrm{ml}$ bottle has been previously reported to be an effective spacer, producing equivalent aerosol deposition and bronchodilation to that obtained from a conventional spacer in older children. ${ }^{511}$ Our results suggest that the absence of a one way valve (as occurs with a bottle) does not adversely affect aerosol deposition but may in fact increase the amount of aerosol delivered. Valveless spacers have been reported to enhance the delivery of aerosol to the lungs in infants with chronic lung disease. ${ }^{12}$ Similarly, absence of a valve may prove beneficial for children as the need to overcome the resistance of the valve on inspiration is obviated.
Although the Aerochamber is less than half the volume of the Babyhaler, equivalent aerosol deposition was obtained from both devices. The choice of spacer size must balance the need for a small volume with the loss of aerosol because of impaction on the side walls which increases as the volume diminishes. ${ }^{13}$ Previous studies have reported that larger doses of aerosol are obtainable from the Babyhaler than the Aerochamber. ${ }^{13}{ }^{14}$ However, these studies measured the drug collected on filter paper interposed after the inspiratory valve of the spacer; thus they reflect the dose of aerosol delivered at the child's mouth and not the amount deposited in the lungs. The reduction in lung aerosol deposition because of the smaller volume of the Aerochamber may be countered by the large dead space in the Babyhaler, thus explaining the equivalence of these spacers.

Characteristics of the child such as their tidal volume, breathing pattern, and technique of spacer usage may further affect drug deposition..$^{16}$ As evidence of this, reduced deposition of aerosol occurred at approximately 50 months of age with all spacers. Reasons for this may be related to the ability of the child to cooperate as well as age dependent differences in pulmonary mechanics. Lower tidal volumes and inspiratory flow rates generated with younger age, decrease pulmonary aerosol delivery resulting in substantially less lung deposition in young children compared to older subjects. ${ }^{17}$

An MDI with mouthpiece rather than facemask has been recommended for children 3-5 years old. The current British Thoracic Guidelines for the management of childhood asthma advise use of a spacer with mask for children under 2 years. ${ }^{18}$ Our study suggests that the mouthpiece and mask produce equivalent aerosol deposition. Although aerosol leakage from the perimeter of the mask where it fits onto the face may result in lower lung deposition, this did not appear to be a problem. However, we were careful to use a well fitting mask that was firmly applied to the face. Choice of the delivery method should be based on the availability and cost of the system as well as the ability and preference of the individual child. Whether a facemask or mouthpiece is selected, the correct technique for use of the delivery system should be carefully demonstrated to the care giver.

Exposure of children to radiation raises ethical concern. However, the total radiation dose for each child in this study was extremely small. The estimated dose of radiation that children were exposed to is far less than that obtained from a single abdominal $x$ ray and may be similar to the amount of naturally occurring radiation that is acquired daily.

The method of aerosol delivery in our study differs from that of an MDI. We have previously developed and tested this delivery system in older children. ${ }^{5}$ The aerosol used was generated via a jet nebuliser that produces particles with a mass median aerodynamic diameter of 2-4 $\mu \mathrm{m}$. Lung deposition of aerosol from an MDI might differ from that attained 
using our delivery system. However, the percentage deposition obtained is not important, but rather the relative deposition from different spacers. As the delivery system was kept constant and the particular spacer varied, a valid comparison of the efficacy of different spacers could be made.

In conclusion, a modified $500 \mathrm{ml}$ plastic bottle produced superior aerosol deposition to that obtained from a conventional small volume valved spacer. The Aerochamber and Babyhaler were equivalent in the amount of pulmonary aerosol deposition produced. Use of a mouthpiece rather than a facemask did not increase the amount of aerosol deposited in the respiratory tract in children older than 3 years. The choice of spacer and use of mask or mouthpiece should be made based on consideration of factors such as patient preference, cost of the device, ability of the care giver or patient to use the spacer correctly, and type of MDI used. Use of a $500 \mathrm{ml}$ modified bottle as a spacer for children requiring inhaled therapy for asthma should be encouraged.

The study was supported by a grant from the Medical Research Council of South Africa (HZ) and GlaxoWellcome. We thank Ms A Toerien and Ms G Brown for help in administering the study, Drs N Braithwaite, C Stanley, and J Te Water Naude for help in recruiting patients, and Mr J Cupido for assistance with construction of the delivery system.

1 Bisgaard H. Aerosol treatment of young children. Eur Respir Rev 1994;4:15-20.

Barnes PJ. Inhaled glucocorticoids for asthma. $N$ Engl f Med 1995;332:868-75.

3 Amirav I, Newhouse MT. Metered dose inhaler accessory devices in acute asthma: efficacy and comparison with devices in acute asthma: efficacy and comparison with 1997;151:876-882.
4 Fugisang G, Pedersen S. Comparison of nebuhaler and nebulizer treatment of acute severe asthma in children. Eur nebulizer treatment of acute
f Respir Dis 1986;69:109-13.

5 Zar HJ, Liebenberg M, Weinberg E, Binns HJ, Mann MD. The efficacy of alternative spacer devices for delivery of aerosol therapy to children with asthma. Ann Trop Paediatr 1998;18:75-9.

6 Mann MD, Binns H, Gallie F, Zar H, Weinberg E, Wynchank S. A method for performing aerosol ventilation scans in infants and young children. Eur F Nucl Med 1998; 25:1129.

7 Zar HJ, Green C, Mann MD, Weinberg EG. A novel method for constructing an alternative spacer. $S$ Afr Med $\mathcal{F}$ 1999;89:40-2.

8 Corr D, Dolovich M, McCormack D, et al. Design and characteristics of a portable breath actuated, particle size selective medical aerosol inhaler. Fournal of Aerosol Science 1982;13:1-7.

9 Bisgaard H, Ahhoj J, Klug B, Berg E. A non electrostatic spacer for aerosol delivery. Arch Dis Child 1995;73:226-30.

10 Clark DJ, Lipworth BJ. Effects of multiple actuations, delayed inhalation and antistatic treatment on the lung bioavailability of salbutamol via a spacer device. Thorax 1996; 51:835-40.

11 Zar HJ, Brown G, Donson H, Braithwaite N, Mann MD, Weinberg EG. Home-made spacers for bronchodilator therapy in children with acute asthma: a randomised trial. Lancet 1999;354:979-82.

12 Fok TF, Lam K, Chan CK, et al. Aerosol delivery to non-ventilated infants by metered dose inhaler: should a valved spacer be used? Pediatr Pulmonol 1997;24:204-12.

13 Bisgaard H, Ahhoj J, Klug B, Berg E. A non electrostatic spacer for aerosol delivery. Arch Dis Child 1995;73:226-30.

14 Ashurst IC, Ambrose CV, Russell DJ. Pharmaceutical evaluation of a new spacer device for delivery of metered-dose inhalers to infants and young children. Fournal of Aerosol Science 1992;23(suppl 1):499-502.

15 Barry PM, O'Callaghan C. The effect of breathing pattern on the output of budesonide from spacers. Eur Respir $\mathcal{f}$ 1996;9(suppl 73):432s.

16 Wildhaler JH, Devadason SG, Eber E, et al. Effects of electrostatic charge, flow, delay and multiple actuations on the in vitro delivery of salbutamol from different small volume spacers for infants. Thorax 1996;51:985-8.

17 Tal A, Golan H, Grauer N, Aviram M, Albin D, Quastel MR. Deposition pattern of radiolabelled salbutamol inhaled from a metered-dose inhaler by means of a spacer with mask in young children with airway obstruction. $\mathcal{F}$ Pediatr 1996;128:479-84.

18 The British guidelines on asthma management: 1995 review and position statement. Thorax 1997;52(suppl 1):S1-21. 